\title{
Application of problem-based learning and case-based learning integrated method in the teaching of maxillary sinus floor augmentation in implant dentistry
}

\author{
Yunfei Liu ${ }^{1}$, Yamei Xu ${ }^{1}$, Yueheng $\mathbf{L i}^{\text {Corresp., } 1}$, Qingqing Wu ${ }^{\text {Corresp. } 1}$ \\ ${ }^{1}$ Stomatological Hospital of Chongqing Medical University; Chongqing Key Laboratory of Oral Diseases and Biomedical Sciences; Chongqing Municipal Key \\ Laboratory of Oral Biomedical Engineering of Higher Education, Chongqing, China \\ Corresponding Authors: Yueheng Li, Qingqing Wu \\ Email address: YF@hospital.cqmu.edu.cn, 501190@hospital.cqmu.edu.cn
}

Background. Teaching of maxillary sinus floor augmentation (MSFA) is challenging for dental educators due to the varied sinus anatomy and high rate of complications. The method integrating problem-based learning and case-based learning (PBL-CBL method) may be more effective than the traditional teacher-centered method. The aim is to evaluate the efficacy of the PBL-CBL method in teaching MSFA. Materials \& Methods. Ninety-two students who received training between 2015 and 2017 at the Department of Implant Dentistry were divided randomly into an experimental group and a control group. Students in the experimental group were trained using the PBL-CBL method, while those in the control group were trained using the traditional teacher-centered method. After three months of training, a survey of the students' opinions about the corresponding teaching method was carried out through a feedback questionnaire. A theory test was used to investigate the level of MSFA knowledge among the students. A case analysis was designed to test whether the students can apply the knowledge in solving new problems. Results. Compared with the control method, the PBL-CBL method resulted in higher scores in both the theory test and the case analysis, and obtained a higher rate of satisfaction among the students. The difference in scores between the two methods were statistically significant $(P<0.01)$, Conclusion. The PBL-CBL method resulted in better results regarding acquisition of academic knowledge, ability in case analysis and student satisfaction compared with the teacher-centered method. It may be a promising mode for teaching complex surgical techniques in implant dentistry and other dental fields. 
1 Application of problem-based learning and case-based learning integrated method in the

2 teaching of maxillary sinus floor augmentation in implant dentistry

3 Yunfei Liu ${ }^{1}$, Yamei Xu${ }^{1}$, Yueheng $\mathrm{Li}^{1 *}$, Qingqing $\mathrm{Wu}^{1 *}$

$4 \quad{ }^{1}$ Stomatological Hospital of Chongqing Medical University, Chongqing Key Laboratory of Oral

5 Diseases and Biomedical Sciences, Chongqing Municipal Key Laboratory of Oral Biomedical

6 Engineering of Higher Education, Chongqing 400015.

$7 *$ To whom correspondence should be addressed.

$8 *$ Corresponding Author:

9 Yueheng Li, DDS, Stomatological Hospital of Chongqing Medical University, Chongqing

10 621000, China. Tel: +8615025308523, Email: YF@hospital.cqmu.edu.cn

11 Qingqing $\mathrm{Wu}, \mathrm{DDS}, \mathrm{PhD}$, Stomatological Hospital of Chongqing Medical University,

12 Chongqing 621000, China. Tel: +8615680885701, Email: 501190@hospital.cqmu.edu.cn 


\section{Abstract}

14 Background. Teaching of maxillary sinus floor augmentation (MSFA) is challenging for dental

15 educators due to the varied sinus anatomy and high rate of complications. The method

16 integrating problem-based learning and case-based learning (PBL-CBL method) may be more

17 effective than the traditional teacher-centered method. The aim is to evaluate the efficacy of the

18 PBL-CBL method in teaching MSFA.

19 Materials \& Methods. Ninety-two students who received training between 2015 and 2017 at the

20 Department of Implant Dentistry were divided randomly into an experimental group and a

21 control group. Students in the experimental group were trained using the PBL-CBL method,

22 while those in the control group were trained using the traditional teacher-centered method. After

23 three months of training, a survey of the students' opinions about the corresponding teaching

24 method was carried out through a feedback questionnaire. A theory test was used to investigate

25 the level of MSFA knowledge among the students. A case analysis was designed to test whether

26 the students can apply the knowledge in solving new problems.

27 Results. Compared with the control method, the PBL-CBL method resulted in higher scores in 
28 both the theory test and the case analysis, and obtained a higher rate of satisfaction among the

29 students. The difference in scores between the two methods were statistically significant

$30 \quad(\mathrm{P}<0.01)$,

31 Conclusion. The PBL-CBL method resulted in better results regarding acquisition of academic

32 knowledge, ability in case analysis and student satisfaction compared with the teacher-centered

33 method. It may be a promising mode for teaching complex surgical techniques in implant

34 dentistry and other dental fields.

35 
Introduction

37 Dental implants are widely applied for rehabilitation of partial and complete edentulism

38 (Pjetursson, 2012; Zitzmann, 2013; Fillion, 2013). As an essential part of dental education,

39 teaching of implant dentistry has been required by multiple academic institutions (De Bruyn,

40 2009; Stanford, 2005). Pneumatization of the maxillary sinus and atrophy of the alveolar ridge

41 are common scenarios following the loss of posterior maxillary teeth. To develop these sites for

42 dental implant placement, maxillary sinus floor augmentation (MSFA) are routinely performed.

43 However, teaching MSFA faces great challenges. First of all, anatomy of maxillary sinus is

44 highly varied, such as the aberrations of the maxillary septum and the different pathological

45 conditions of Schneiderian membrane (Malkinson \&Irinakis, 2009; Irinakis, Dabuleanu

46 \&Aldahlawi, 2017). The prevalence of maxillary septum is between $16 \%$ and $48 \%$ (Naitoh, 2009;

47 Rosano, 2010; Güncü, 2011). The occurrence of Schneiderian membrane perforation is 10-60\%

48 of all procedures (Becker, 2008; Nolan, Freeman\&Kraut, 2014). In addition, MSFA is

49 technically sensitive because the surgical access to the sinus floor is quite limited, making

50 teaching and training difficult. Many educators in the field of implant dentistry are working hard 
51 to find a suitable teaching method for MSFA so as to increase the teaching efficacy.

52 Given that most students learning MSFA are resident doctors, the teaching method of MSFA

53 should take the characteristics of adult learning into consideration. Hallmarks of adult learning

54 are the use of authentic problems to guide small-group discussions (Abela, 2009) and learning

55 techniques facilitating retention of interest in the subject (Major \&Palmer, 2001). The traditional

56 teacher-centered teaching approach delivers basic and clinical sciences information primarily in

57 a lecture format. Students learning in this way tend to rely on repetition and memorization

58 (Major\& Palmer, 2001). Problem-based learning (PBL) and case-based learning (CBL) have

59 emerged as powerful tools in reforming traditional teaching methods. PBL in medical education

60 uses the patient's problem as a stimulator for students to learn problem-solving skills while CBL

61 is a group discussion-styled teaching approach based on analysis of authentic clinical cases

62 (Tayem, 2013; Jackson, 2003; Donner \& Bickley, 1993; Finucane, Johnson \& Prideaux, 1998).

63 PBL and CBL engage students in their own learning, focus on concrete scenarios like problems

64 or cases, and emphasize the development of thinking skills (Hofsten, Gustafsson \& Haggstron,

65 2010; Chan, Hsu \& Hong,2008; Hakkarainen, Saarelainen \& Ruokamo,2007). They comply with 
66 the key elements of adult learning theory (Nadershahi N, 2013), making them the promising

67 instructional methods to teach MSFA.

68 However, CBL or PBL present some limitations in teaching MSFA if applied alone. First of all,

69 CBL may not provide an organized view of knowledge as it situates knowledge in real-world

70 contexts in a piecemeal way. The students, who usually don't have pre-established knowledge,

71 may find it difficult to learn a new subject using CBL method alone (Williams, 2005). On the

72 other hand, as it requires students to learn background knowledge by solving problems during

73 the class session, PBL is effective for students who don't have pre-established knowledge

74 provided the problems are properly framed (Williams, 2005). However, the teacher who poses a

75 problem without cases or context may find it difficult to frame the problems and engage

76 students' interests. Cases can help contextualize the problems and framed the knowledge in a

77 logical and organized way (Allchin D,2013). PBL is primarily student-driven whereas CBL is

78 collaborative (Williams, 2005), which means the teachers can be more intimately and directly

79 involved by CBL, making it easier for them to frame and contextualize the problems. Therefore,

80 PBL and CBL are mutually complementary. PBL can amplify the basic virtues of CBL, while 
81 CBL can facilitate framing and contextualizing the problems. This study is to combine the two

82 methods and evaluate the efficacy of the combined PBL-CBL method in teaching MSFA.

\section{Materials \& Methods}

84 Students

85 This study was conducted according to the guidelines set forth by the Declaration of Helsinki

86 and approved by the Ethics Committee of the Affiliated Stomatological Hospital of Chongqing

87 Medical University (No. KQJ201816). Written informed consent was obtained from all students.

88 Ninety-two clinicians who received training between 2015 and 2017 at the Department of

89 Implant Dentistry, the Affiliated Stomatological Hospital of Chongqing Medical University,

90 were included in this study. All the students were junior doctors, aged between 25 to 30 years,

91 and were granted with a full-time undergraduate degree from dental colleges in China. No

92 students had any experience or training in MSFA. The students were randomly allocated into an

93 experimental group and a control group. In the experimental group, the students (25 males and

9421 females) were trained using the PBL-CBL method, while the students in the control group (24

95 males and 22 females) were trained using the traditional teacher-centered method. Both groups 
96 were trained for a period of 3 months.

\section{Teaching methods}

98 All students attended class sessions on five topics for MSFA, "1. Anatomy of Maxillary Sinus",

99 “2. Pre-surgical Assessments and Treatment Plan”, “3. Surgical Principles and Procedures”, “4.

100 Points for Attention during MSFA", and "5. Management of Complications". The curriculum of

101 MSFA was completed in eighteen sessions, with each session lasting for forty minutes. In the

102 control group, the students sequentially attended the sessions in the form of teacher-centered

103 lectures, and the role of the teacher was to dispense final form knowledge. There was no

104 scheduled discussion time during or beyond the class session. In the experimental group, the

105 students attended no formal lectures. Instead the students were divided into small groups of 3 or

1064 members. Discussions about the topic were held in each of the 18 sessions. The role of the

107 teacher shifted from conventional authority to a case narrator and an expert guide for discussion.

108 The total duration and number of sessions were the same in the two groups.

109 The teaching method in the experimental group is described as follows to show how CBL and

110 PBL were combined. The parenthetical abbreviations at the end of the sentences, namely (PBL) 
111 or $(\mathrm{CBL})$, indicates that the activity or method described in the sentence is drawn from PBL or

112 CBL.

113 1. Assignment of pre-class work and introduction of typical cases and problems

114 Before the class session started, the teacher asked the students to do pre-class work related to the

115 topic of the course, such as searching and reading information in papers, books or on authorized

116 websites (PBL). The teacher prepared one or more typical clinical cases in advance to engage the

117 students' interests on the topic (CBL). During the class session, the teacher presented the cases to

118 provide the students with detailed information about the patient's chief complaint, history of

119 present illness, medical history, intraoral examination, cone-beam computed tomography scan

120 and the research plaster model (CBL). The teacher would interrupt the case by raising problems

121 related to the topic of the course (PBL). The students were asked to use existing clinical data and

122 discuss in small groups. Then each group made comprehensive analysis, proposed effective

123 treatment plans, analyzed possible risks and identified ways to avert such risks, and explained

124 their reasons $(\mathrm{PBL})$.

125 2. Group reports and Q\&A session 
126 At the last session of each of the five topic, the teacher commented on the outcome of

127 discussions reported by each group (CBL) and relevant questions were raised by both the teacher

128 and the students (PBL). The teacher guided the discussion on some questions while leaving the

129 others for the students to think about (PBL). These were open-ended questions that would arouse

130 the students' interest in learning and encourage them to further explore the issues (PBL).

131 Questions about the next topic were raised and framed in the context of cases by the teacher to

132 cue the need for background knowledge (CBL and $\mathrm{PBL})$. The students would then begin to

133 search for and read materials related to these questions and make preparations for discussion in

134 the sessions of the next topic (PBL). Meanwhile, the teacher would offer guidance to the students

135 on how to retrieve information online or from the library (PBL).

136 3. Summary of MSFA and development of a treatment plan for a complex case

137 At the final session, the teacher presented a complex case and raised questions on the five topics.

138 The students were asked to discuss the case in groups and make a treatment plan. The group

139 leader then summarized their discussion and presented a summary on behalf of the group

140 members. The teacher analyzed and summarized the key points and determined the final 
141 treatment plan together with all the students.

\section{Evaluation methodology}

143 The outcomes of different teaching methods were evaluated in the following three ways. Two

144 teachers from the department of implantology graded the exams. The graders were blinded to the

145 name of the students and the group they belonged to.

146 1. Anonymous questionnaire

147 After the training, anonymous questionnaires made by the researchers compromised of nine

148 questions were filled out by both the students from the experimental group and the control group.

149 The detailed information of the questionnaire was revealed in Table 1.

150 2. Theory test

151 At the end of training, students took the final exam which included four questions, namely

152 indications for sinus augmentation, preoperative assessments of MSFA, procedures for MSFA,

153 and management of maxillary sinus membrane perforation. The total score were 100 points, 25

154 points for each question.

155 3. Case analysis 
156 After the theory test, the teacher presented a new case which was different from the cases

157 discussed earlier in the class. The teacher provided the students with detailed information about

158 the patient and the students were required to answer a series of questions about the key points

159 that had been taught or discussed in the class sessions in a written form. Finally, the papers were

160 graded. The test paper and the scale of marks were attached as supplement 1.

161 Statistical analysis

162 Pearson's chi-squared test was used to analyze the difference in gender and the students'

163 opinions about the teaching methods between the experimental group and the control group. The

164 scores of the theory test and the case analysis were expressed as mean \pm standard deviation (SD).

165 One-way ANOVA was applied to analyze the difference in scores between the experimental

166 group and the control group. All tests were two-sided, and $\mathrm{p}<0.05$ was considered significant.

167 Statistical analyses were performed using the statistical package SPSS (version 20.0, IBM,

168 Armonk, NY, USA).

\section{Results}

170 A total of ninety-two students (49 men and 43 women), aged between 25 and 33 years 
171 (mean:28.6 years), were included in this study. No students were lost to follow-up. There was no

172 significant difference between the control group and experimental group with regard to gender

$173(\mathrm{p}=0.883)$. All students followed the schedule and attended the lectures or discussion on time.

174 Table 1 shows the survey results of the questionnaire. The rate of satisfaction with the PBL-CPL

175 method is higher than that with the control method in all the items except for "This approach

176 decreases extracurricular workload”.

177 Table 2 shows the scores of the theory test and the case analysis. Compared with the teacher-

178 centered approach, the PBL-CBL method resulted in higher scores in both the theory test and the

179 case analysis. The score differences between the two studied groups were statistically significant

180 for both the theory test $(\mathrm{P}<0.01)$ and case analysis $(\mathrm{P}<0.01)$. The students in the experimental

181 group presented a generally better understanding of MSFA based on the theory test and case

182 analysis.

183 Discussion

184 PBL and CBL have been described as promising tools for medical and dental education and have

185 been used in varied fields of dental education (Donoff, 2006; Major \& Palmer,2001; Wang et 
186 al.,2008; Koh et al.,2008; Thistlethwaite et al.,2012; Tomaz et al.,2015). To maximize the effect

187 of PBL and CBL, our study applied a teaching method integrating PBL and CBL in teaching

188 MSFA, which achieved higher efficacy than the traditional teacher-centered method. According

189 to the students' feedback, more than $90 \%$ of the students believed that the combined method

190 made learning more targeted, enhanced their problem-solving ability, improved their clinical

191 skills and raised their teamwork awareness. These results are consistent with the results of other

192 studies in which the combined method was applied in leadership training or biochemistry

193 experiment teaching (Dong \& Zeng, 2017; Ginzburg SB et al., 2018). In general, the PBL-CBL

194 method was shown to be more effective than the teacher-centered method in teaching MSFA.

195 Combined PBL-CBL may be a useful model for teaching complex oral surgery in dentistry.

196 Previous studies pointed out that CBL was not effective in conveying existing knowledge system,

197 which was typically conveyed in didactic teacher-centered approached (Allchin D,2013; Jamker,

198 2006). In this study, we interrupted cases with a series of well-contextualized questions or

199 problems. Then the students were asked to use reference book, library and online resources to

200 solve the problems. In this way we contextualized the knowledge in authentic cases and 
201 embodied the rationale for learning by posing problems. Previous studies reported that PBL was

202 able to cover approximately 80 percent of what could be accomplished in a didactic approach in

203 the same period (Albanese MA,1993; Berkson L 1993). The result of the theory test in our study

204 showed that students in the PBL-CBL group had formed a comprehensive and organized

205 understanding of MSFA. The PBL-CBL method was even advantageous over the didactic

206 approach in conveying existing knowledge system, suggesting that problems well-framed in

207 cases could cover standard curricular content.

208 In addition to basic knowledge, the result of case analysis further showed that students in the

209 PBL-CBL group were more likely to use the acquired knowledge spontaneously to solve new

210 problems than those who acquired the same information through lectures. The rate of satisfaction

211 with the PBL-CPL method was higher than that with the control except for the item "This

212 approach decreases extracurricular work". Although this was only a subjective feeling of the

213 students, it did show that the PBL-CBL approach was positively accepted among students.

214 Students who thought the PBL-CBL approach did not decrease extracurricular workload may

215 have spent more time searching for information. Therefore, in order to take full advantage of the 
216 PBL-CBL methodology, the faculty members should be trained more vigorously to lead

217 discussion groups and provide assistance to develop the students' capacity in searching for and

218 generalizing information.

219 There were still some imitations in study design and methodology in this preliminary study. We

220 assumed that PBL and CBL were mutually complementary and could achieve the best effect

221 when combined. However, no control groups using PBL or CBL alone were included in this

222 study, and we were not able to determine whether the hybrid method was superior to PBL or

223 CBL alone. To gain feedback about the hybrid method, a Yes/No scale was used in the

224 questionnaire, which only resulted in rough calculations. A Likert Scale would be more

225 appropriate and accurate to scale responses and detect difference in survey research. In addition,

226 one study was inadequate to prove the efficacy of the PBL-CBL method. Further randomized

227 controlled trial was needed to confirm the effect of the PBL-CBL method.

228 Conclusion

229 The students learning MSFA with the PBL-CBL method exhibited better acquisition of academic

230 knowledge and higher competence in case analysis compared with those learning MSFA with the 
231 traditional teacher-centered method. This research suggested that the PBL-CBL method be a

232 promising new mode for teaching complex surgical techniques in implant dentistry and other

233 dental fields.

234 
235 References

236 Pjetursson BE, Thoma D, Jung R, Zwahlen M, Zembic A. 2012. A systematic review of the

237 survival and complication rates of implant- supported fixed dental prostheses (FDPs) after a

238 mean observation period of at least 5 years. Clin Oral Implants Res 23(Suppl 6):22-38.

239 Zitzmann NU, Krastl G, Weiger R, Kühl S, Sendi P. 2013. Cost-effective- ness of anterior

240 implants versus fixed dental prostheses. J Dent Res 92:183S-8.

241 Fillion M, Aubazac D, Bessadet M, Allègre M, Nicolas E. 2013. The impact of implant treatment

242 on oral health related quality of life in a private dental practice: a prospective cohort study.

243 Health Qual Life Outcomes 11:197.

244 De Bruyn H, Besseler J, Raes F, Vaneker M. 2009. Clinical outcome of overdenture treatment on 245 two nonsubmerged and nonsplinted Astra Tech Microthread implants. Clin Implant Dent Relat

246 Res 11:81-9.

247 Stanford CM. 2005. Application of oral implants to the general dental practice. J Am Dent Assoc 248 136:1092-100.

249 Malkinson S, Irinakis T. 2009. The influence of interfering septa on the incidence of

250 Schneiderian membrane perforations during maxillary sinus elevation surgery: A retrospective

251 study of 52 consecutive lateral window procedures. Oral Surg 2:19-25.

252 Irinakis T, Dabuleanu V, and Aldahlawi S. 2017. Complications During Maxillary Sinus

253 Augmentation Associated with Interfering Septa: A New Classification of Septa.Open Dent J 11:

$254 \quad 140-150$.

255 Naitoh M, Suenaga Y, Kondo S, Gotoh K, Ariji E.2009. Assessment of maxillary sinus septa 256 using cone-beam computed tomography: etiological consideration. Clin. Implant Dent. Relat. 257 Res. 11(Supp11):e52-e58. 
258 Rosano G, Taschieri S, Gaudy JF, Lesmes D, Del Fabbro M. 2010. Maxillary sinus septa: A 259 cadaveric study. J. Oral Maxillofac. Surg. 68(6):1360-1364.

260 Güncü GN, Yildirim YD, Wang HL, Tözüm TF. 2011. Location of posterior superior alveolar 261 artery and evaluation of maxillary sinus anatomy with computerized tomography: A clinical 262 study. Clin. Oral Implants Res. 22(10):1164-1167.

263 Becker ST, Terheyden H, Steinriede A, Behrens E, Springer I, Wiltfang J. 2008. Prospective 264 observation of 41 perforations of the Schneiderian membrane during sinus floor elevation. Clin. 265 Oral Implants Res. 19(12):1285-1289.

266 Nolan PJ, Freeman K, Kraut RA. 2014. Correlation between Schneiderian membrane perforation 267 and sinus lift graft outcome: A retrospective evaluation of 359 augmented sinus. J. Oral 268 Maxillofac. Surg.;72(1):47-52.

269 Abela J. Adult learning theories and medical education: a review. Malta Med J 2009;21(1):11-8.

270 Major C, Palmer B. Assessing the effectiveness of prob- lem-based learning in higher education: 271 lessons from the literature. Acad Exchange Qtrly 2001;5(1):1-6.

272 Tayem YI. 2013. The impact of small group case-based learning on traditional pharmacology 273 teaching. Sultan Qaboos Univ Med 13(1): 115-20.

274 Jackson J.2003. Case-based learning and reticence in a bilingual context: perceptions of business 275 students in Hong Kong.System, 31(4):457-69.

276 Donner RS, Bickley H. 1993.Problem-based learning in American medical education: an 277 overview. Bull Med Libr Assoc, 81(3):294-8.

278 Finucane PM, Johnson SM, Prideaux DJ. 1998. Problembased learning: its rationale and efficacy. 279 Med J Aust, 168:445-8.

280 Hofsten A, Gustafsson C, Haggstron E.2010. Case seminars open doors to deeper understanding: 281 nursing students’ experiᄀences of learning. Nurse Educ Today, 30(6):533-9 
282 Chan WP, Hsu CY, Hong CY .2008. Innovative case-based inte $\neg$ grated teaching in an

283 undergraduate medical curriculum: development and teachers' and students' responses. Ann

284 Acad Med Singapore, 37(11):952-6.

285 Hakkarainen P, Saarelainen T, Ruokamo H .2007. Towards meaningful learning through digital 286 video-support $\neg$ ed, case-based teaching. Australas J Educ Technol,23(1):87-109.

287 Nadershahi NA, Bender DJ, Beck L, Lyon C, Blaseio A. An overview of case-based and 288 problem-based learning methodologies for dental education. J Dent Educ. 2013,77(10):1300-5.

289 Williams B. 2005.Case-based learning: a review of the literature - is there scope for this 290 educational paradigm in prehospital education? Emerg Med, 22:577-81.

291 Allchin D. 2013.Problem- and Case-Based Learning in Science: An Introduction to Distinctions, 292 Values, and Outcomes. CBE_Life Sciences Education 12, 364-372.

293 Donoff RB. 2006.It is time for a new Gies report. J Dent Educ, 70(8):809-19.

294 Wang G, Tai B, Huang C, Bian Z, Shang Z, Wang Q, Song G. 2008. Establishing a 295 multidisciplinary PBL curriculum in the School of Stomatology at Wuhan University. J Dent 296 Educ,72(5):610-5.

297 Koh GC, Khoo HE, Wong ML, Koh D. 2008.The effects of problem-based learning during 298 medical school on physician competence: a systematic review. CMAJ ,178(1):34-41.

299 Thistlethwaite JE, Davies D, Ekeocha S, Kidd JM, Macdougall, Matthews P, Purkis J, Clay D. 300 2012.The effectiveness of case-based learning in health professional education. A BEME 301 systematic review: BEME guide no. 23. Med Teach, 34:e421-44.

302 Tomaz JB, Mamede S, Filho JM, Roriz Filho Jde S, van der Molen HT.2015. Effectiveness of an 303 online Problem-Based learning curriculum for training family medical doctors in Brazil. Educ 304 Health, 28(3):187-93.

305 Dong J \& Zeng P. 2017. The Application of CBL Teaching Combined with PBL Teaching 
306 Method in Biochemistry Experiment Teaching. 10.2991/meici-17.2017.126.

307 Ginzburg SB, Deutsch S, Bellissimo J, Elkowitz DE, Stern JN, Lucito R. 2018. Integration of 308 leadership training into a problem/case-based learning program for first- and second-year 309 medical students. Adv Med Educ Pract,9:221-226.

310 Jamkar A, Yemul V, Singh G. 2006. An integrated teaching program with student-centered, 311 case-based learning. Med Educ 40:466-7.

312 Albanese MA.1993. Problem-based learning: a review of literature on its outcomes and 313 implementation issues. Acad Med 68(1):52-81.

314 Berkson L. 1993. Problem-based learning: have the expectations been met? Acad Med 315 68(10):579-88. 


\section{Table $\mathbf{1}$ (on next page)}

Comparisonof Average Scores of the Two Groups ( ' $x \pm S, n=46$ ) 
1

2 Table 1 Opinions on the PBL-CBL Method (PBL-CBL) and the teacher-centered teaching 3 method (control)

\begin{tabular}{|c|c|c|c|}
\hline \multirow[t]{2}{*}{ Items Surveyed } & \multicolumn{2}{|c|}{ Rate of Satisfaction } & \multirow[t]{2}{*}{ P value } \\
\hline & PBL-CBL & control & \\
\hline 1. I like this approach & $91.3 \%$ & $76.1 \%$ & 0.0482 \\
\hline 2. This approach is efficient & $89.1 \%$ & $73.9 \%$ & 0.0601 \\
\hline 3. This approach decreases extracurricular work & $65.2 \%$ & $87.0 \%$ & 0.0145 \\
\hline 4. This approach makes learning more targeted and more interesting & $95.7 \%$ & $60.9 \%$ & $<0.001$ \\
\hline 5.This approach enhances my ability to analyze and solve problems & $93.5 \%$ & $39.1 \%$ & $<0.001$ \\
\hline 6. This approach helps me master theoretical knowledge & $87.0 \%$ & $82.6 \%$ & 0.5616 \\
\hline 7.This approach helps me improve clinical skills & $95.7 \%$ & $52.2 \%$ & $<0.001$ \\
\hline 8. This approach facilitates clinician-patient communication & $87.0 \%$ & $73.9 \%$ & 0.1148 \\
\hline 9. This model emphasizes more on teamwork & $93.5 \%$ & $32.6 \%$ & $<0.001$ \\
\hline
\end{tabular}


Table 2 (on next page)

Evaluation of the PBL-CBL Integrated Method by theExperimental Group $(n=46)$ 
1 Table 2 Comparison of Average Scores of the Two Groups ( $\bar{x} \pm S, n=46)$

\begin{tabular}{|c|c|c|c|c|}
\hline Group & Gender & Theory Test & Case Analysis & Total score \\
\hline \multirow[t]{2}{*}{ Experimental Group $(n=46)$} & Male: $n=25$ & $80.69 \pm 3.25$ & $76.30 \pm 3.01$ & $78.50 \pm 3.21$ \\
\hline & Female: $n=2$ & & & \\
\hline \multirow[t]{2}{*}{ Control Group $(n=46)$} & Male: $n=24$ & $76.34 \pm 3.46$ & $72.19 \pm 2.82$ & $74.27 \pm 3.07$ \\
\hline & Female: $n=2$ & & & \\
\hline F Value & & 38.432 & 45.443 & 40.304 \\
\hline$P$ & & $<0.01$ & $<0.01$ & $<0.01$ \\
\hline
\end{tabular}

2 (experimental group exposed to the PBL-CBL method; control group in the traditional teacher-

3 centered curriculum)

4 